However, it was an enjoyable read as an adjunct to core texts. I would also recommend this book to patients with a relatively high level of education and an interest in learning more about anxiety.

David McLaughlan Bloomsfield Centre, Guys Hospital, South London and Maudsley Trust, London SE1 9RT, UK. Email: david.mclaughlan@slam.nhs.uk

doi: 10.1192/bjp.bp.112.117127

\section{Years of the IPA}

The Centenary History of the Internationa Psychoanalytical Association 1910-2010

Evolution and Change

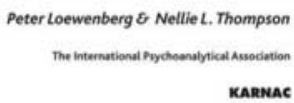

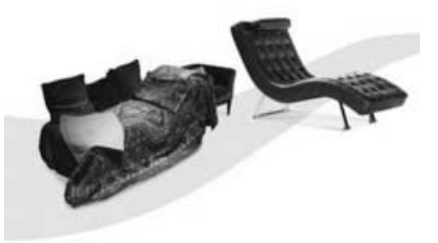

100 Years of the IPA. The Centenary History of the International Psychoanalytical Association, 1910-2010: Evolution and Change

Edited by Peter Loewenberg \& Nellie L. Thompson. £45.00 (pb). 570pp. ISBN: 9781905888160 Karnac Books. 2011.

The International Psychoanalytical Association (IPA) was founded in 1910. At that stage there were fewer than 100 members, most of whom were friends or colleagues. Despite its modest size there was no shortage of prestige - it was founded by Sigmund Freud, on an idea proposed by Sándor Ferenczi. The first president was Carl Jung and its first secretary was Otto Rank. Other founding members included Max Eitingon and Karl Abraham. Today, it is an association that counts 12000 psychoanalysts as members and works with 70 constituent organisations. It is recognised as the world's primary accrediting and regulatory body for psychoanalysis and takes an active role in the development of psychoanalytic thought and practice throughout the world.

2010 was the centenary year of the IPA and is marked by the publication of this book, a collection of essays from 41 of the member nations, each describing their own history and development within their particular geographical area. The psychoanalytic world is broadly split into four within the book: Europe, North America, Latin America and Asia and Oceania together.

The book begins with an essay from the Viennese branch of the IPA and the subsequent chapters trace the story of the growth and development of not just the IPA, but psychoanalytic thought and practice, outwards from Vienna and across the globe. It thus provides not just a history of the constituent member organisations, but an interesting account of the interplay between the social, cultural and political factors that both shaped, and were shaped by, the spread of an understanding of the unconscious.

For those with an interest in psychoanalysis or psychotherapy, the rich historical detail and the linking of advances to the context of the time provides both a fascinating read and much to consider in terms of how and why psychoanalysis in the reader's own patch may have reached where it has. For those working within the National Health Service (NHS) in the UK today, the book serves as a timely reminder of how the history of psychoanalysis is one of periods of enthusiasm and uptake followed by waning interest or attack, often to the point that it seems as though survival is threatened. Splits and divisions are commonplace. Throughout, however, is a clear message that in some form or another psychoanalytic thought and practice not only survives, but spreads and grows.

The collected histories of the member organisations provide many examples of how survival often requires history to be processed to allow the required change. Also highlighted is the need for innovation and to remain responsive to the environment of the time, including a flexible approach as to how treatments and training are not only funded, but structured. Edith Kurzweil is quoted in the history of German psychoanalysis, making the point that a country gives rise to the form of psychoanalysis it needs. The example of the growth of psychoanalysis in China since the end of the Cultural Revolution (where there is now a rigorous 3-year analytic training for psychiatrists and psychologists) illustrates not just this sentiment, but the importance of creating a training programme capable of providing the treatments that a country can use at that particular point in time.

For the reader without a particular interest in psychoanalysis or psychotherapy there is still much of interest and relevance within the book, especially in the current climate of enforced change and upheaval within the NHS. Reading the book leaves one in no doubt as to the importance of the emotional life of an organisation and how this can affect its functioning. The value of holding onto the history, in particular the importance of the 'primal scene' of an organisation to its subsequent growth and development, is illustrated time and again. The histories of those groups who had their primal scenes or conceptions in the product of a forced marriage or a brutal takeover - and how those traumas affected not just their emotional life, but their smooth running until the trauma was processed - seems particularly relevant when similar events seem to be happening within different parts of the NHS today. It is in this area that the book, and the IPA, provides an eloquent and convincing argument for the importance of continually developing a rigorous and structured approach to understanding the present through an honest appraisal of past and current emotions, conscious or otherwise.

Paul MacAllister Specialist Registrar, Wells Road Centre for Community Forensic Psychiatry, Wells Road, Nottingham NG3 3AA, UK. Email: paul.macallister@nottshc. nhs.uk

doi: 10.1192/bjp.bp.111.107169

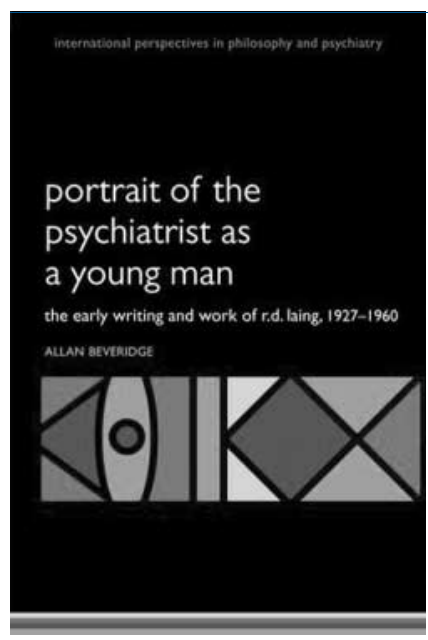

\section{Portrait of the Psychiatrist} as a Young Man The Early Writing and Work of R. D. Laing, 1927-1960

By Allan Beveridge. Oxford University Press. 2011. f39.99 (pb). $384 \mathrm{pp}$ ISBN: 9780199583577

The memory of R. D. Laing, the most famous British psychiatrist to date, refuses to fade almost 25 years after his death. In 2011, a plaque was unveiled in his honour at his childhood home in 